\title{
Linking production paradigms and organizational approaches to production systems
}

\author{
S. Carmo-Silva, A.C. Alves, F. Moreira \\ Centre for Production Systems Engineering, University of Minho, Campus de Gualtar, 4700-057 Braga, \\ Portugal (scarmo@dps.uminho.pt)
}

\begin{abstract}
Manufacturing system design and operation is critical to achieve strategic company objectives. This must aim fitting manufacturing systems capabilities to the different demand market environments, having in consideration the different approaches and strategies that should be used. In this paper we develop a framework for characterizing production system conceptual models and linking them to both production paradigms and organizational approaches to production, such as lean and agile manufacturing. The conceptual models identified are useful for aiding to implement organizational approaches and fit manufacturing systems to manufacturing requirements determined by different product demand patterns.
\end{abstract}

Keywords: Manufacturing systems, agile and lean, production paradigms and models

\section{Introduction}

Production systems must be designed and managed to best fit market demand requirements. Critical to such design and management is the nature of demand. It is therefore relevant to characterize demand and, accordingly, to link this to production paradigms and these to production approaches and systems.

\section{Production Paradigms}

\subsection{Mass Production}

It is common to refer as mass production the production paradigm that addresses a demand market where demand for a product is large and is kept so over long time periods, i.e. it is predictable and stable. In this paradigm, production is continuous, at a flow rate which ideally matches product demand.

Production systems of the mass production paradigm have as a key performance objective meeting demand at low cost per unit manufactured.
Thus, to take advantage of scale economies not only the production system as a whole, but also their workstations, main equipment and tooling are dedicated to one product. Therefore, the life time of such a system is linked to the life time of the product to which it is dedicated.

\subsection{Repetitive Production}

We can also envisage an evolution of the market demand to a situation of variable and less predictable demand, in lower volumes and shorter product life cycles than in mass production. Therefore a dedicated system to each product is economically unacceptable. Thus, a variety of products, repeatedly required over time, with somewhat different production requirements, may have to be manufactured in the same production system with characteristics different from those of mass production systems. This requires flexible forms of production and/or of organizing production. This organization is usually based on interlinked and relatively autonomous subsystems, usually cells of 
several types [1], or on function oriented production units. Flexible production is achieved through flexible equipment subject to tool changing for multi-task handling and is usually operated by multiskilled operators. Flexible manufacturing may also be used in some circumstances. Several tools can be used for designing, adjusting, managing and continuously improving manufacturing systems' configuration. These include approaches, techniques and methods associated with Lean Manufacturing, Total Quality Management, Continuous Improvement and set-up reduction. Additionally we should refer, at operations planning and control, the use of several order release and materials flow control mechanisms [2] and scheduling methods and systems [3] .

Repetitive Production (RP) is based on repeatedly required products whose demand is predictable but in volumes that do not justify mass production systems. This definition is in line with what is presented by Bradford [4], and MacCarthy and Fernandes [5], but differs from the view of other authors.

Two fundamental instances of RP can be identified with basis on the production flow pattern, i.e. Repetitive Uniform Flow Production (RUFP) and Repetitive Intermittent Flow Production (RIFP). In RUFP different products are manufactured together, in a mixed manner, during a given planned production period, at a uniform flow rate. This rate matches and is synchronized with demand rate for the period. We could say that RUFP attempts to mass produce a variety of products in low volumes as if they were a single product. The RUFP repetitive production paradigm instance is itself frequently referred as repetitive production [6] without including the RIFP instance. The RIFP paradigm instance is based on the repetitive but independent, i.e. not mixed, manufacture of products which were also manufactured in the past. The flow of production is not uniform but, on the contrary, intermittent, i.e. based on the flow of independent batches. It is common to refer RIFP systems as multi-model production systems in opposition to the RUFP systems which can be identified as mixed model ones [7].

Not disregarding the importance of low cost per unit, typical of mass production systems, key performance objectives of repetitive production systems are the efficient use of manufacturing resources and good customer service measured mainly in two dimensions, namely timely delivery of products and product quality. A key design feature of a repetitive production system is its capability to jointly manufacture, in the same production period, a variety of products required in variable but predictable demand.

\subsection{Non-repetitive Production}

Repetitive production is still a valid paradigm in today's market environment and is likely to continue to be so for many years. However it is loosing importance and rapidly giving place to the nonrepetitive one, probably the most common paradigm in the near future.

Non-repetitive production is mainly linked with unpredictable and turbulent demand markets for unique products, different from others previously manufactured, i.e. not repeated. This means that a company cannot reasonably forecast, or precisely identify, products before costumer orders are placed. This is both the result of global competition and increased and varying customer needs. Although ordering is not likely to be repeated, this does not mean that only a single or a small number of product units will be required. In fact, a customer may order a large quantity of a new, unpredictable, customized product.

Non-repetitive production is, surely, associated with product customization. This means that there is the involvement of the customers in the specification or customization of products. Product customization may lead to an approach to production referred to as mass customization. The concept was initially put forward by Davies [8] and brought into Production and Operations Management area by Pine [9] who defines mass customization as the ability of a firm to produce a variety of customized products quickly, on a large scale, and at a cost comparable to mass production. A typical case of mass customization has been reported by Kotha [10] for the production of mass customized bicycles based on individual customer anthropometric measures and other customer requirements. Duray et al. [11] argues that mass customization is associated with modular product design and manufacture. This is dependent on modular options and variants, or differentiation enablers as they are called by Tseng [12]. The customer choice of differentiation enablers can be facilitated through product configurators [13]. The essence of modular concept is to design develop and manufacture parts that can be combined in the maximum number of ways [14]. Product customization can be realized at different levels. Mintzberg [15] distinguishes three: pure, tailored and 
standardized. Pure means products designed and produced from scratch for each customer. In this level of customization mass customization may be not met. Standardized means the assembly of products from a set of standard components according to individual customer needs; and tailor customization is altering a basic product design to suit customer needs. Gilmore and Pine [16] refers four approaches to product customization dependent on the degree of customer involvement in the customization process and degree of product customizability.

Mass customization has, in many instances, elements of production repeatability reason why the manufacturing organization solutions for mass customization may be based not only on the nonrepetitive paradigm but also on the repetitive one.

In the non-repetitive production, production requirements can only be established after customer orders are known. In some cases, due to market unpredictability, even resources to carry out production tend to be "assembled" only after the business opportunity appears. This is typical of Virtual Enterprises paradigm [17].

To be competitive, companies must always aim at low cost per unit and good product quality. This also applies to non-repetitive production. However, for companies to sustain competitiveness ability under turbulent or unpredictable market demands they must be fast responsive and ensure good customer service. To achieve such performance objectives, a key feature of non-repetitive production systems is agility to easily adapt to, or accommodate, frequent changing production requirements as a result of constantly varying product demand. This adaptation requires flexible forms of work organization, system flexibility and, frequently, the ability for fast system reconfiguration

Although we have identified only three main production paradigms that embrace the whole spectrum of product demand, from stable to unstable and unpredictable markets, these paradigms can lead to quite a few different production systems conceptual models. The next sections focus on such models and relate them to a range of organizational approaches to manufacturing.

\section{Production Systems Conceptual Models}

Production systems conceptual models can be defined and related with production paradigms to meet the fundamental requirements of production determined by market demand. Such definition and relation, require identification of important system related conceptual variables capable of allowing a clear characterization and differentiation of each conceptual model. Moreover the relationship between any model, production paradigm and organizational production approach, such as lean or agile manufacturing, must be clear. Five such variables were selected, namely product variety, systems reconfigurability, reconfigurability environment, product repeatability and workflow continuity, each of which instantiated at two levels. Fig. 1 shows the alternative values of each variable characterizing fifteen production systems conceptual models (PCM). For example PCM 8 represents a virtual reconfigurable system simultaneously addressing production of several different products under the repetitive production paradigm and leveled mixed uniform flow production. This is a novel configuration suited to agile manufacturing [18]. Model 9 differs in that batched or intermittent production instead of leveled mixed flow is used. This particular model configures virtual manufacturing cells as defined by McLean et al. [19].

Production systems reconfigurability can be understood as a measure of the easiness of manufacturing system reconfiguration to suit manufacture changing requirements. Although system reconfigurability may be important for manufacturing agility this may be brought about by ways other than system reconfiguration. In fact this can be carried out, for example, by fast and flexible tool changing systems [20] or by the provision of several forms of flexibility related with materials flow system, workstations, people skills and management.

We can think of two types of system reconfigurability environment: virtual and physical. Virtual systems reconfigurability is the ability of reconfiguring a system through temporary reallocation of available or accessible distributed manufacturing resources to a system, without physically displacing them. Distributed resources mean that they are locally or globally apart and are autonomous, i.e. control their own processes. Virtual systems may be based on company internal resources or, otherwise, be based on a wide range of resources globally available. In this case the virtual system can be seen as part of a Virtual Enterprise.

Physical reconfigurability of manufacturing systems has similarities to the virtual reconfigurability with two important differences 


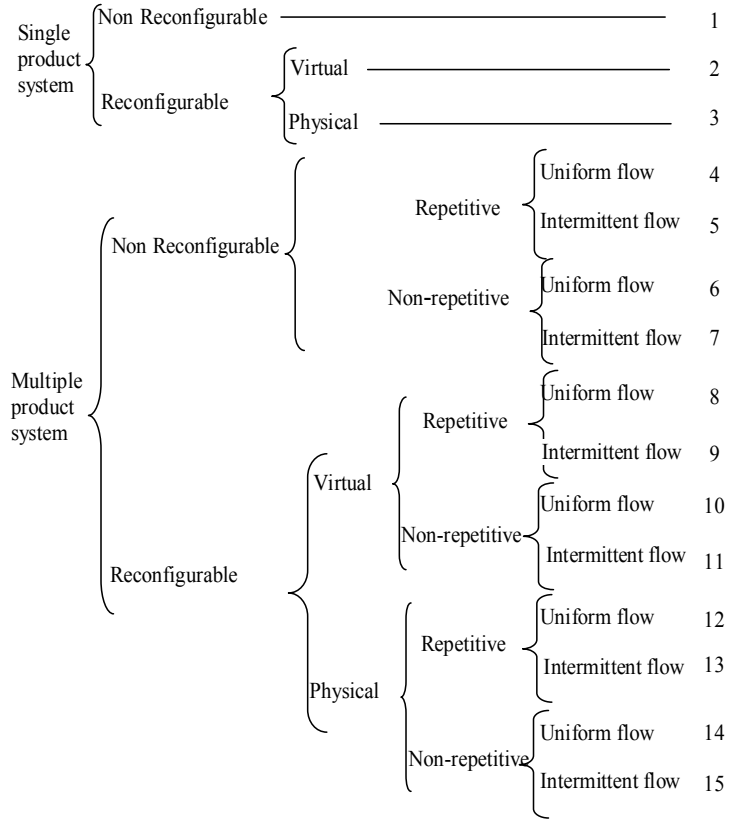

Fig. 1. Conceptual variables and the fifteen production systems conceptual models set.

associated with two dimensions: system and resource dimensions. First, in the reconfiguration process, the manufacturing resources can be displaced from their original locations and physically replaced to best fit changes in manufacturing requirements. Second, the resources themselves can be reconfigured to fit manufacturing requirements. Important fitting measures seek to stream line or at least simplify the work and materials flow during production.

System reconfiguration can be done on a production order basis, regularly, at time intervals, or whenever important product demand changes occur.

\section{Organizational Approaches to Production}

Five major organizational approaches to production are identified. These are: mass, batch, job, lean and agile. The relationships between these, the production systems conceptual models and production paradigms are illustrated in table 1 .

\subsection{Mass Production}

The mass production approach is strictly related with the mass production paradigm and, therefore, implements a system which during its life time is dedicated to the production of a single product. The system is designed to achieve the expected maximum demand rate for the product. When production rate cannot be adjusted and synchronized with product demand rate then inventory is created. Sometimes, due to high processing similarity of a few products they can share, on a time basis, usually after minor system adjustments, the same mass production system and, therefore, they may be seen as if they were the same product.

Nowadays, due to global competition and constantly changing markets, mass production of discrete products involving assembly is uncommon. We still can encounter mass production of parts and also of products from process industries. In the former case manufactured is carried out by either automatic machines or transfer lines.

PCM 1, Fig. 1, characterizes the conceptual model associated with the mass production approach.

\subsection{Batch Production}

In this organizational approach to production several different products are ordered and production is always carried-out in batches, in a repetitive intermittent manner. Clearly, batch production is closely linked with the RIFP instance of the repetitive paradigm. Production requirements are usually known in advance and production processes and management are carefully established to achieve both technological and operational efficiency.

The nature of batch production systems have an in built ability to deal with multi-product processing requirements and may have variable degrees of flexibility. This can result from exploring the versatility of manned or unmanned workstations. In the former case we are talking about traditional batch production and in the latter one about Flexible Manufacturing Systems [21]. Therefore, some nonreconfigurable FMS may be seen as instances of this organizational approach.

We can link Batch Production to three PCM models, namely PCM 5, PCM 9 and PCM 13.

\subsection{Job Production}

In this approach, systems are designed to deal with requirements of the non-repetitive production paradigm. This means that an enormous variety of products should be handled. For this, systems must be highly flexible, exploring the use of versatile equipments, with jobs usually visiting either stand 
Table 1

Relationships between organizational approaches, production systems conceptual models and production paradigms

\begin{tabular}{|c|c|c|c|c|c|c|c|c|}
\hline $\begin{array}{c}\text { Production } \\
\text { Conceptual } \\
\text { Model (1) }\end{array}$ & $\begin{array}{c}\text { Production } \\
\text { paradigm }\end{array}$ & $\begin{array}{c}\text { Organizational } \\
\text { approach }\end{array}$ & $\begin{array}{c}\text { Market } \\
\text { predictability }\end{array}$ & $\begin{array}{c}\text { Volume } \\
\text { per product } \\
\text { ordered) }\end{array}$ & $\begin{array}{c}\text { Product } \\
\text { variety }\end{array}$ & Flow & $\begin{array}{c}\text { Reconfigu } \\
\text { rability }\end{array}$ & $\begin{array}{c}\text { Product } \\
\text { customizability }\end{array}$ \\
\hline 1 & Mass & Mass & Stable & Large & None & C & None & None \\
\hline 2 & Non-repetitive & Agile & Turbulent & Medium & Small & C & Virtual & High \\
\hline 3 & Non-repetitive & Agile & Unpredictable & Medium & Small & C & Physical & Medium \\
\hline 4 & Repetitive & Lean & Predictable & Medium & Small & C & None & Low \\
\hline 5 & Repetitive & Batch & Predictable & Medium & Small & I & None & Low \\
\hline 6 & Non-repetitive & Agile & Unpredictable & One-of-a-kind & Large & C & None & Medium \\
\hline 7 & Non-repetitive & Job & Unpredictable & One-of-a-kind & Large & I & None & Medium \\
\hline 8 & Repetitive & Agile & Unpredictable & Small & Medium & C & Virtual & Medium \\
\hline 9 & Repetitive & Batch & Unpredictable & Small & Medium & I & Virtual & Medium \\
\hline 10 & Non-repetitive & Agile & Turbulent & One-of-a-kind & Large & C & Virtual & High \\
\hline 11 & Non-repetitive & Agile & Turbulent & One-of-a-kind & Large & I & Virtual & High \\
\hline 12 & Repetitive & Lean & Unpredictable & Small & Large & C & Physical & Medium \\
\hline 13 & Repetitive & Batch & Unpredictable & Small & Medium & I & Physical & Medium \\
\hline 14 & Non-repetitive & Agile & Turbulent & One-of-a-kind & Large & C & Physical & High \\
\hline 15 & Non-repetitive & Agile & Turbulent & One-of-a-kind & Large & I & Physical & High \\
\hline
\end{tabular}

(1) According to Fig. 1; Flow: C- continuous, I - Intermittent

alone workstation or cells, or functional sections, or both, in a random manner, according to processing requirements of each job. Both flexible stand alone programmable workstations and manned universal machines are frequently used. Scheduling is critical for achieving production objectives and coordination of production. The typical production system configuration associated with this approach is a jobshop. Systems efficiency is usually poor in these systems. The PCM 7 model is the one most related with the Job Production approach. The associated production paradigm is clearly non-repetitive.

\subsection{Lean Production}

It is common to say that Lean Manufacturing focuses on waste elimination and lean thinking [22]. Lean manufacturing was firstly explored in the Toyota car factories under the name of Toyota Production System (TPS) which is based on principles and techniques of Just-in-Time (JIT) production [23]. An evolution of the TPS to a more advanced approach intensifying collaboration between companies, from design to manufacture and delivery, has been referred to as Lean Extended [24].

Lean manufacturing may be seen as an attempt to apply the mass production paradigm and, more specifically, levelled uniform flow production, to the repetitive production environment, from raw materials to delivery. An important objective is to achieve high productivity and, at the same time, synchronize production with demand for a variety of products.

The objectives and organization strategies of Lean production allow identifying this approach mainly with the PCM 4 and PCM 12 conceptual models.

\subsection{Agile Production}

The Agile production approach addresses production of customized products and, in particular, of the mass customization type.

Huang and Nof [25] state that enterprise agility must be accomplished through agility in business, organizational, operational and logistic systems. In many instances, to achieve agility production manufacturers need to interact or collaborate through the internet and intranets with partners, including suppliers and even competitors, as well as with customers.

Due to the fact that the agile approach focuses on production of customized products, the nonrepetitive production paradigm is predominant. This is why seven of the eight Production Conceptual Models, associated with non-repetitive production, fit the agile approach requirements as can be seen from table 1. The only other case is PCM 8 that configures a repetitive system model already described in section 3 as suitable for agile manufacturing. 


\section{Conclusions}

Mass, repetitive and non-repetitive production paradigms were reviewed, clarified and extended having in mind recent developments in manufacturing strategies and approaches to fit production systems to demand markets and environments of today and tomorrow. Based on the production paradigms and a set of critical variables, relevant to system design and operation, a set of fifteen production systems conceptual models were characterized. These may be seen as reference models to implement, at manufacturing level, several organizational approaches to production. In this work such approaches were reduced to five briefly described and to a great extent coincident with some well known concepts that include lean and agile manufacturing. A clear interrelation between production conceptual models, organizational approaches to production and production paradigms was shown.

\section{Acknowledgements}

University of Minho is partner of the EU-funded FP6 Innovative Production Machines and Systems (I*PROMS) Network of Excellence. http://www.iproms.org

\section{References}

[1] Silva SC and Alves A. In: Ferreira JJP (Ed.), A framework for understanding Cellular Manufacturing Systems. e-Manufacturing: Business Paradigms and Supporting Technologies, Kluwer, 2004, pp. 163-172.

[2] Fernandes NO and Carmo-Silva S. Generic POLCAA Production and Materials Flow Control Mechanism for Quick Response Manufacturing. International Journal of Production Economics (article in press).

[3] Pinedo M. Scheduling - Theory, Algorithms and Systems, Prentice-Hall Inc., 1995.

[4] Bradford MJ. Repetitive Manufacturing: Benefits, benefits. IIE Solutions (2001), pp. 38-43.

[5] MacCarthy BL and Fernandes FCF. A Multidimensional classification of production systems for the design and selection of production planning and control systems. Production Planning and Control (2000) Vol. 11, No. 5, pp. 481-496.

[6] Toni AD and Panizzolo R. Repetitive Manufacturing Planning and Control Systems: a framework for analysis. Production Planning and Control (1997) Vol. 8, No. 5, pp. 500-508.

[7] Scholl A. Balancing and Sequencing of Assembly Lines. Physica-Verlag, 1995.

[8] Davis SM. Future Perfect. Addison-Wesley, Reading,
MA, 1987

[9] Pine BJ. Mass Customization: the new frontier in Business competition. Harvard Business School Press, 1993.

[10] Kotha S. Mass customization: implementing the emerging paradigm for competitive advantage. Strategic Management Journal, Vol. 16 (1995) 21-42.

[11] Duray R Ward PT Milligan GW and Berry WL. Approaches to Mass Customization: Configurations and empirical validations. Journal of Operations Management, Vol. 18, No. 6, pp. 605-625, 2000.

[12] Tseng M Jiao J. Mass Customization. In Salvendy (ed) Handbook of Industrial Engineering, 3rd edition. John Wiley and Sons, USA, 2001.

[13] Bourke KE. Product Configurators: Key enablers for Mass customization, 2000.

[14] Starr MK. Modular Production a New Concept, Harvard Business Review,Vol. 43, No. 6, pp. 131-142, 1965.

[15] Mintzberg H. Generic Strategies: Towards a comprehensive framework. Advances in Strategic Management, Vol. 5, pp. 1-67, 1988.

[16] Gilmore JH and Pine BJ. The four faces of customization. Harvard Business Review Vol. 75, No. 1 (1997) 91-101.

[17] Camarinha-Matos LM and Afsarmanesh, H. The Virtual Enterprise Concept. In L M Camarinha-Matos and $\mathrm{H}$ Afsarmanesh, Infrastructures for Virtual Enterprises: Networking Industrial Enterprises Kluwer Academic Publishers, 1999, pp 3-14.

[18] Hormozi, A. M. Agile Manufacturing. In 37 International Conference proceedings of APICS (APICS), San Diego, (1994) 216-218.

[19] McLean CR, Bloom HM and Hopp TH. The Virtual Manufacturing Cell. In: Proceedings of the 4th IFAC/IFIP Conference on Information Control Problems in Manufacturing Technology, 1982, 105111.

[20] Silva SC. Strategies and Fundamental Structures for FMS tool Flow Systems. In Camarinha-Matos LM. (Ed.) Re-Engineering for Sustainable Industrial Production. Chapman \& Hall, 1997.

[21] Tempelmeier $\mathrm{H}$ and Heinrich Kuhn, Flexible Manufacturing Systems: decision support for design and operation. John Wiley and Sons, 1993.

[22] Womack JP. and Jones DT. Lean Thinking. Siman \& Schuster, New York, USA, 1996.

[23] Monden Y. Toyota production System. Industrial Engineering and Management Press, Institute of Industrial Engineers, 1983.

[24] Schonberger RJ. Lean Extended. Industrial Engineer, 2005, 26-31.

[25] Huang C-Y. and Nof S. Enterprise Agility: a view from the PRISM lab. International Journal of Agile Management Systems, Vol. 1, No. 1, (1999), 51-59. 